\title{
MAIS EMPREGOS COM MENOS AGLOMERAÇÃO: PROPOSTA DE DESONERAÇÃO DA FOLHA COM ÊNFASE NAS MENORES JORNADAS',2
}

Marcos Hecksher ${ }^{3}$

Carlos Henrique Corseuil ${ }^{4}$

\section{INTRODUÇÃO: A PANDEMIA E O BAIXO NÍVEL DE OCUPAÇÃO}

Até o fim do primeiro semestre de 2020, o mundo havia contabilizado meio milhão de mortes por Covid-19, das quais aproximadamente 60 mil no Brasil, onde a primeira foi registrada em março. Além de todas as vidas perdidas, a pandemia do novo coronavírus provocou recessão global, com destruição de postos de trabalho ainda náo totalmente dimensionada. Em maio de 2020, a população ocupada no mercado de trabalho brasileiro teve aproximadamente 10 milhôes de pessoas a menos do que tivera três ou doze meses antes. ${ }^{5}$ Mais da metade da população de 14 anos ou mais do país ficou sem trabalhar, e a maioria das mulheres ficou fora da força de trabalho, sem nem mesmo procurar emprego, o que não ocorria há mais de três décadas.

O país tomou medidas emergenciais com ampla cobertura para mitigar o impacto econômico da pandemia sobre o emprego dos trabalhadores com vínculo formal e a renda dos demais adultos. ${ }^{6}$ Agora, novas açôes precisam ser desenhadas e adotadas para viabilizar a necessária recuperação do emprego a partir do nível historicamente baixo que foi atingido. Tais açôes, sob a perspectiva incerta do tempo de espera até o advento de uma vacina e a imunização massiva da população, devem conciliar condições para a mínima propagação do vírus e incentivos à máxima preservação e abertura de postos formais de trabalho.

Não se sabe ao certo a duração dos impactos da pandemia, tampouco como será a retomada da atividade econômica. É provável, no entanto, que a retomada ocorra de forma oscilante -

1. DOI: http://dx.doi.org/10.38116/bmt69/politicaemfoco2

2. Os autores agradecem a contribuição de Miguel Foguel para este artigo, haja vista sua participação na elaboração da versão reduzida dessa proposta que aparece em Ipea (2020).

3. Assessor especializado na Diretoria de Estudos e Políticas Sociais (Disoc) do Ipea. E-mail: <marcos.hecksher@ipea.gov.br>.

4. Técnico de planejamento e pesquisa na Disoc/lpea.E-mail: <carlos.corseuil@ipea.gov.br>.

5. Segundo a Pesquisa Nacional por Amostra de Domicílios Contínua do Instituto Brasileiro de Geografia e Estatística (PNAD Contínua/ IBGE), a média móvel da população ocupada caiu 3,3 milhões entre fevereiro-março-abril e março-abril-maio, o que implica queda de 9,9 milhões entre os meses de fevereiro e maio. Acumulando-se variações como essa em intervalos de três meses, chega-se a uma queda de 10,0 milhões entre maio de 2019 e maio de 2020.

6. Em 29 de junho, o Ministério da Economia (ME) divulgou que acordos temporários de redução de jornada ou de suspensão de contratos formais haviam resultado até então em pagamentos do Benefício Emergencial de Preservação do Emprego e da Renda relativos a 11,7 milhões de empregos. Por sua vez, o Auxílio Emergencial, destinado a trabalhadores informais e desempregados, segundo a Dataprev, tinha sido pago a 65,2 milhões de requerentes até 26 de junho. 
devido à possibilidade de novas medidas de isolamento social ou do próprio comportamento precaucional de consumidores e produtores - e heterogênea entre os setores de atividade. Cenários de incerteza como esse podem levar a que muitas empresas assumam pouco risco de (re)contratação de mão de obra, fazendo perdurar baixo nível de ocupação.

É necessário, portanto, pensar em dois tipos de iniciativas. Por um lado, continuar tentando evitar demissóes. Por outro lado, para lidar com as demissóes que não se conseguiu evitar, há de tentar-se reverter o desemprego do maior número possível de pessoas. Afinal, há evidências na literatura de que os novos desempregados em momentos de recessão têm sua trajetória profissional comprometida por ao menos dez anos; período em que aumenta a probabilidade de estarem ou no desemprego ou empregados em postos de baixa qualidade/produtividade.

Nesse contexto, este artigo propóe medidas que incentivem as empresas a (re)contratar mão de obra. A ideia deste trabalho é apresentar alternativas e prover informaçóes que balizem escolhas a serem feitas pela sociedade em suas instâncias decisórias.

Para esse objetivo, a reformulação em curso da proposta do contrato verde e amarelo é uma oportunidade para substituir sua focalização direta em jovens e idosos por uma alternativa voltada a jornadas de trabalho reduzidas, o que incluiria as legalmente consideradas em tempo parcial, mas poderia ir além destas. Com demanda total por horas de trabalho possivelmente deprimida por longo período, as empresas teriam incentivo para dividir entre mais pessoas as novas horas a serem contratadas, promover revezamentos de trabalhadores e, assim, maximizar o nível de emprego com o mínimo de aglomeração. Essa opção seria mais adequada ao novo contexto econômico e sanitário, podendo beneficiar qualquer pessoa e empresa, mas ainda tendente a cobrir proporcionalmente mais os jovens, os idosos e outros grupos severamente atingidos pela crise, como as mulheres e os menos escolarizados.

Os benefícios associados a essa medida podem ir além de facilitar a saída da economia do período de crise, ao se considerar as externalidades positivas referentes a uma redução na frequência de trajetórias profissionais associadas a rotatividade, informalidade e baixos níveis de produtividade e rendimentos.

Após esta introdução, a seção 2 expóe motivaçóes para o foco nas menores jornadas, destacando os grupos a serem possivelmente mais beneficiados. A seção 3 detalha pontos das propostas e simula as medidas com algumas alternativas de parâmetros opcionais, estimativas preliminares de custo e potenciais formas de financiamento. As conclusôes compõem a seção 4.

\section{MOTIVOS PARA DESONERAR AS MENORES JORNADAS}

Um instrumento amplamente utilizado pelos países para incentivar contrataçóes em momentos de recuperação que sucedem crises agudas é a concessão de subsídios ao custo do trabalho. Mais especificamente, esse tipo de programa concede um subsídio temporário às empresas atrelado ao salário relativo a novas contrataçóes. Esse subsídio pode ser operacionalizado por meio de redução temporária de tributos que incidem sobre a folha salarial, com a possibilidade de essa redução ser decrescente ao longo do período de contrato. 
Em contexto de nível de ocupação muito baixo, uma possível forma de estimular maior geração de empregos é fazer com que a contratação de duas pessoas para cada uma trabalhar por vinte horas semanais, por exemplo, seja mais barata do que a contratação de apenas uma pessoa para trabalhar por quarenta horas semanais. Até que toda a população esteja imunizada contra o coronavírus, isso estimularia o revezamento de trabalhadores em dias alternados nas empresas, reduzindo as chances de contágio em locais de trabalho, ruas e meios de transporte públicos. Além disso, essa medida contribuiria para conter a desigualdade e a pobreza extrema no cenário esperado de demanda deprimida por horas totais de trabalho.

Além disso, sem impor qualquer redução ao limite legal de horas de trabalho, eventual redução da jornada média incentivada por esse tipo de desoneração poderia aproximar o Brasil dos países mais desenvolvidos, como os da Organização para a Cooperação e Desenvolvimento Econômico (OCDE), em que as jornadas médias são mais curtas e a produtividade por hora trabalhada é maior (gráfico 1$){ }^{7}$

\section{GRÁFICO 1}

Distribuição das jornadas semanais na OCDE e no Brasil

(Em \%)

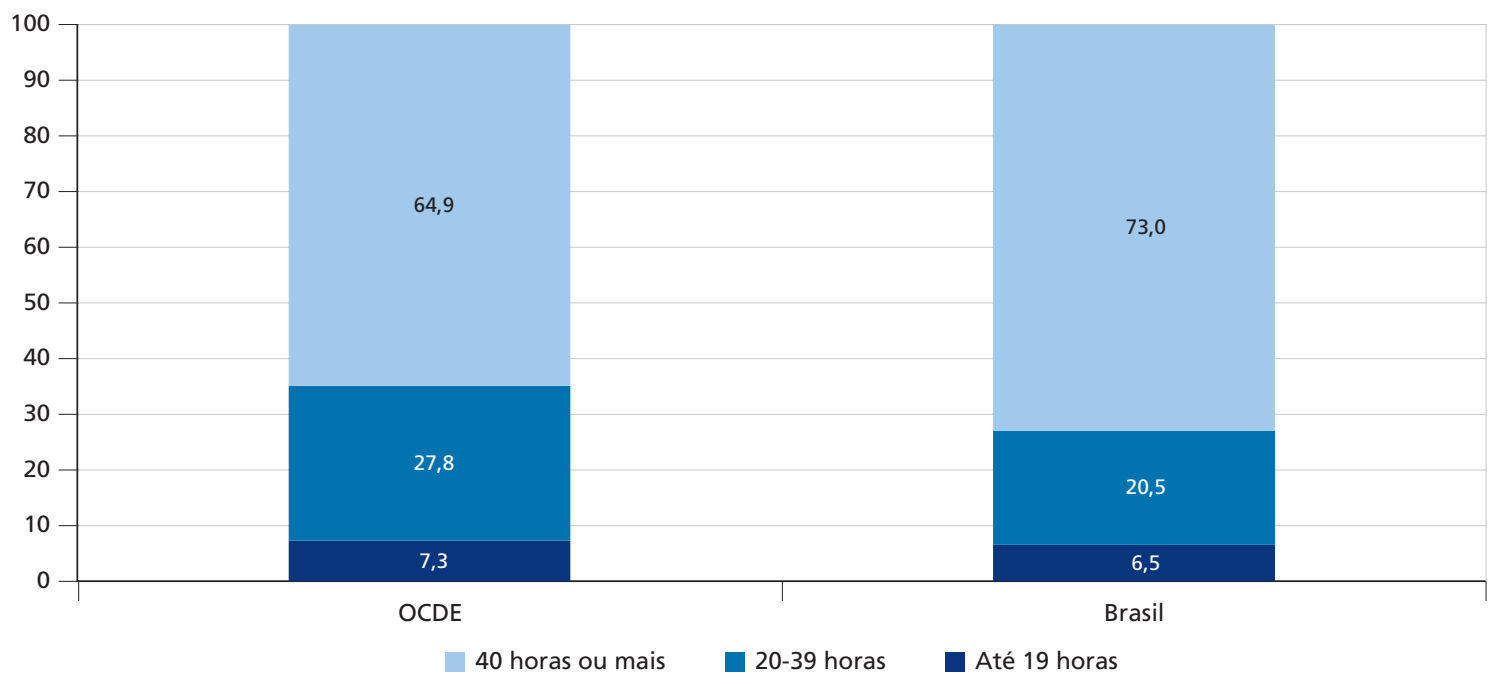

Fonte: OCDE.

Jornadas mais longas continuariam permitidas, mas as mais curtas teriam carga tributária reduzida. Embora o recorte por jornada seja horizontal, podendo beneficiar todos os trabalhadores e empresas, os grupos historicamente contratados com jornadas mais curtas

7. Reis e Costa (2016) mostram que os salários por hora trabalhada são maiores nas jornadas parciais, com diferencial maior quando controlado por diversos fatores. Destacam ainda o aumento acentuado, desde 1980, dos empregos com jornada parcial na OCDE, os quais já alcançavam cerca de $10 \%$ dos homens e $25 \%$ das mulheres. Na Holanda, em torno de $50 \%$ dos trabalhadores estavam em empregos de tempo parcial; na Suíça, 30\% (Garnero, 2016). 
tenderiam a ser os mais beneficiados. Esses grupos incluem os jovens, os idosos, as mulheres, os menos escolarizados e os empregados sem carteira assinada, que teriam um estímulo à sua contratação ou formalização.

Os grupos que mais perderam ocupação na pandemia foram justamente as mulheres, os menos escolarizados, os empregados sem carteira e os trabalhadores de menor renda (Barbosa, Costa e Hecksher, 2020), o que aprofunda desigualdades preexistentes. No caso das mulheres, a maioria passou a náo trabalhar no mercado nem procurar emprego. A suspensáo de aulas presenciais das crianças, aliada à desigualdade na divisão do trabalho de cuidados com a família, pode ser um fator inibidor da participação feminina no mercado. Se as empresas passassem a contratar mais homens e mulheres com jornadas mais curtas, isso viabilizaria equilibrar melhor a divisão de trabalhos no mercado e nos domicílios. Também favoreceria a conciliação, por qualquer trabalhador, entre trabalho e estudo.

Vale insistir que o que se propóe aqui não é restringir compulsoriamente a jornada legal máxima no Brasil, que a Constituição Federal de 1988 (CF/1988) reduziu pela última vez de 48 para 44 horas semanais, o que de fato diminuiu a jornada efetiva (Gonzaga, Menezes Filho e Camargo, 2003). Em vez disso, sem nada impor, o governo poderia incentivar a adesão voluntária a jornadas mais curtas por meio de desoneraçáo que as privilegiasse, conforme foi sugerido por Neri (2000). Isso reduziria o custo relativo do fator trabalho no caso desses contratos, de modo a induzir maior número de contrataçóes.

Havendo vantagens suficientes em contratar apenas uma pessoa em tempo integral ou em aumentar a carga horária de uma pessoa já experiente e conhecida em certa função na empresa, continuaria sendo possível firmar contratos de até 44 horas semanais. No caso oposto, se essas esperadas vantagens não compensassem a economia de tributos da alternativa de ter mais trabalhadores em jornadas curtas, essa última opção se tornaria atrativa, ao menos enquanto houvesse muitos desempregados dispostos a trabalhar em tempo parcial. O desejado aquecimento da economia tenderia a tornar o incentivo cada vez menos efetivo e, ao mesmo tempo, cada vez menos necessário.

Enquanto houver muita gente de todas as qualificações sem trabalho remunerado, o incentivo será socialmente benéfico e deverá interessar aos empregadores. Em maio, além de a maioria da população de 14 anos ou mais estar sem trabalhar, em quase um terço $(32 \%)$ dos domicílios brasileiros, nenhum morador tinha qualquer renda de trabalho (Carvalho, 2020).

Jornadas mais curtas podem servir como porta de entrada nas empresas, pois, em geral, quanto maior o tempo no mesmo emprego de um trabalhador, maior é sua chance de cumprir jornadas mais longas. O gráfico 2 mostra que, entre os trabalhadores formais e informais, há menos de um mês em seus empregos, $41,5 \%$ têm jornadas semanais de menos de quarenta horas. Por sua vez, entre os que acumulam dois anos ou mais em um emprego, apenas 25,3\% trabalham menos que quarenta horas por semana. 
GRÁFICO 2

Jornadas por grupo de tempo no emprego (trabalhadores formais e informais) (Em \%)

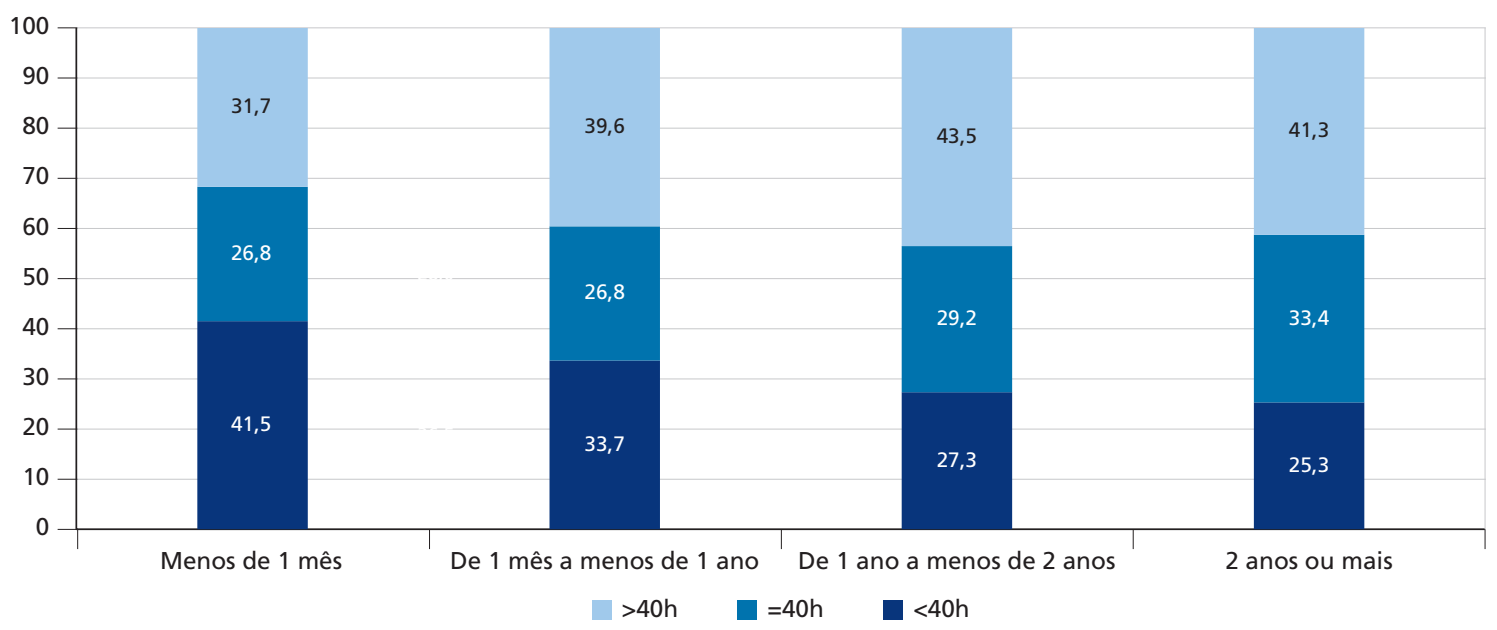

Fonte: PNAD Contínua/IBGE.

O gráfico 3 indica que, entre os trabalhadores mais jovens e os mais velhos, as jornadas de menos de quarenta horas semanais são mais frequentes. Com isso, a desoneração aqui proposta poderia atender a todos os grupos etários, mas tenderia a ser mais benéfica àqueles de 18 a 29 anos cobertos na proposta inicial do governo para a medida provisória (MP) do contrato verde de amarelo, assim como aos de 55 anos ou mais, que os legisladores incluíram no projeto de conversão em lei antes que este perdesse apoio e fosse retirado.

GRÁFICO 3

Jornadas semanais por idade (trabalhadores formais e informais) (Em \%)

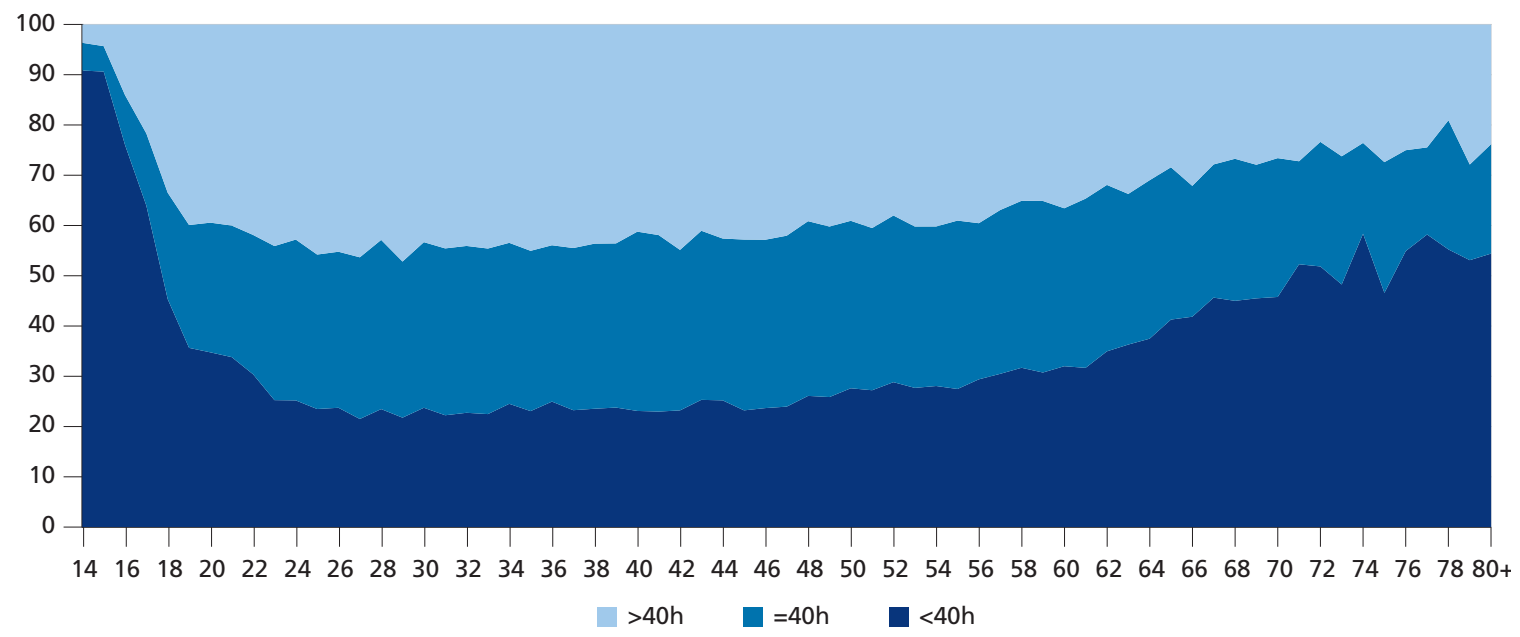

Fonte: PNAD Contínua/IBGE. 
Quando se comparam os trabalhadores formais e informais por grau de instrução registrado na PNAD Contínua, quanto maior a escolaridade, maior tende a ser o percentual com jornada igual ou acima de quarenta horas semanais (gráfico 4). Os mais vulneráveis, com menor remuneração no mercado e mais atingidos pela Covid-19, são os que têm mais contratos de jornada menor que $40 \mathrm{~h}$, chegando a $89,7 \%$ entre os que possuem menos de um ano de estudo. Entre os que apresentam curso superior completo, a proporção cai para 27,7\%.

GRÁFICO 4

Jornadas semanais por escolaridade (trabalhadores formais e informais) (Em \%)

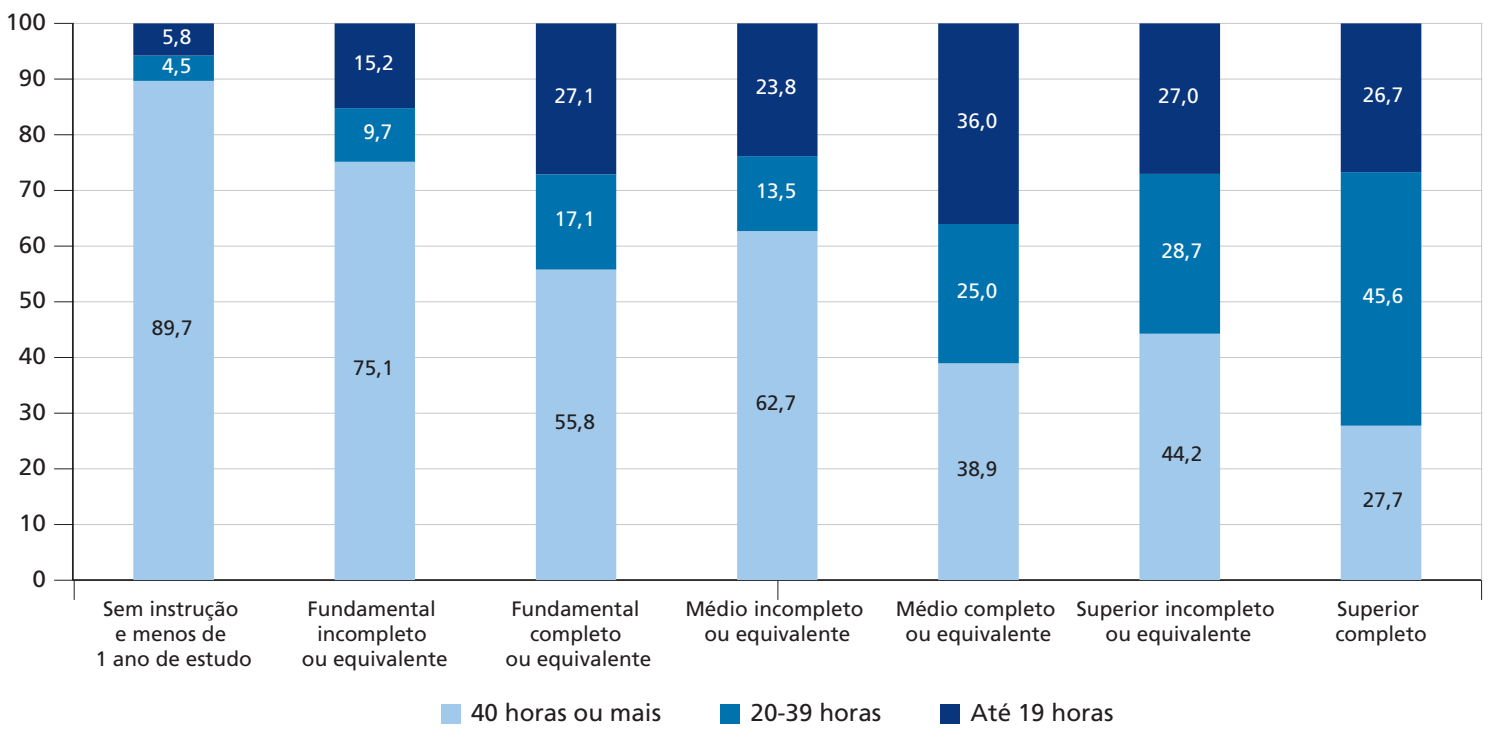

Elaboração dos autores.

Na PNAD Contínua, apenas 9,0\% dos empregados do setor privado com carteira trabalham por menos de quarenta horas semanais (gráfico 5). Por sua vez, entre os empregados do setor privado sem carteira, essa proporção salta para 36,5\%. Desonerar as jornadas mais curtas pode ser um meio para tornar formalizáveis parte dos empregados sem carteira e, ao mesmo tempo, distribuir por mais pessoas as horas formalmente contratadas. 
GRÁFICO 5

Jornadas por formalidade do emprego no setor privado

(Em \%)

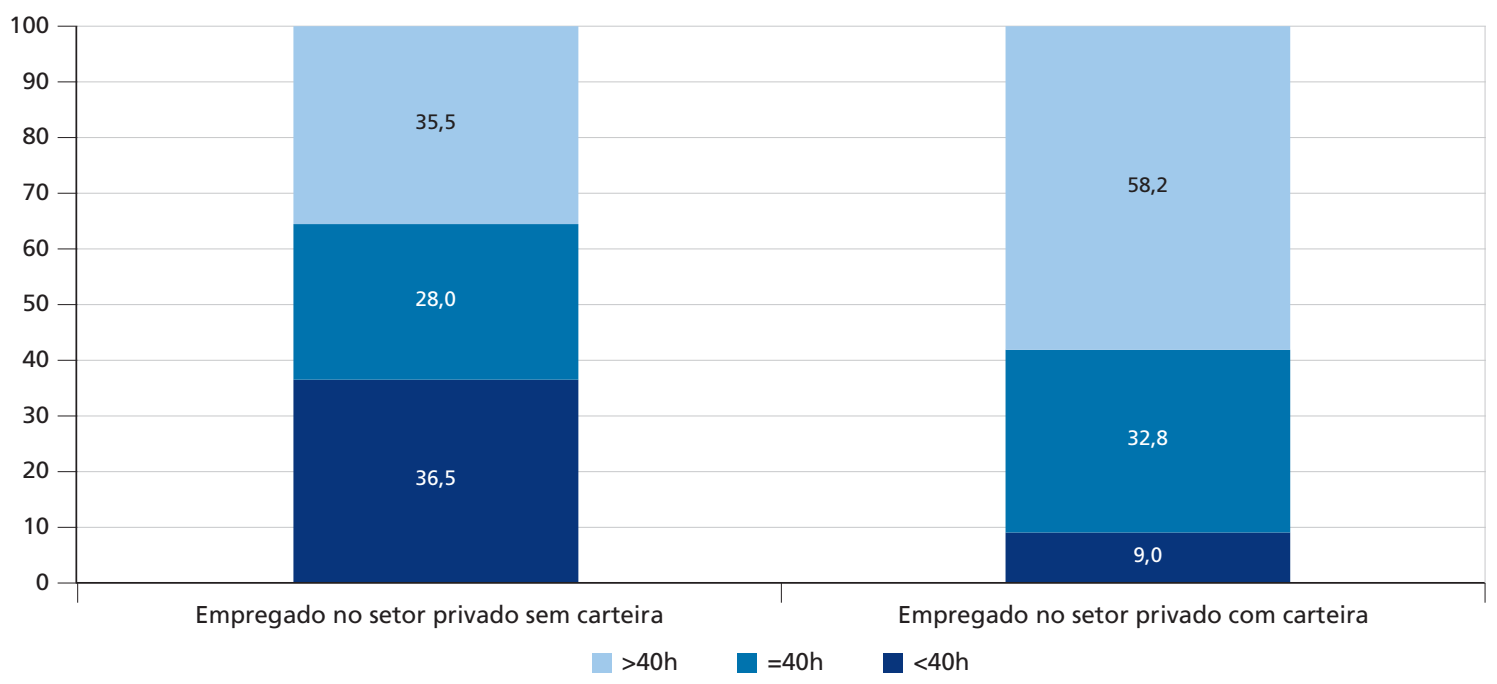

Elaboração dos autores.

\section{DETALHAMENTO DA PROPOSTA E ALTERNATIVAS}

\subsection{Considerações sobre público-alvo}

Trabalhadores: para dar mais incentivos a contrataçóes de trabalhadores vulneráveis, o subsídio pode ser concedido somente para trabalhadores não empregados (no setor formal), ${ }^{8}$ bem como ser atrelado a faixas mais baixas de salário ou aos primeiros reais de salários em faixa mais ampla. Por exemplo, poderia pensar-se em um limite de 3 salários mínimos (SMs), com o objetivo de beneficiar a faixa correspondente a hipossuficiência na MP no 936, de 1o de abril de 2020 .

Como o aumento do desemprego durante a crise deve ocorrer de forma generalizada, a elegibilidade para o programa não se restringiria somente a grupos demográficos específicos - por exemplo, os jovens contemplados na versão original da proposta de contrato verde e amarelo.

Empresas: a fim de mitigar possíveis efeitos indesejáveis de programas de subsídios salariais - tais como o de substituição de trabalhadores subsidiados por não subsidiados e o de desperdício de subsídios para contrataçóes que ocorreriam até mesmo sem o programa -, o subsídio apenas seria concedido a contrataçóes em empresas que experimentaram variação negativa do número de trabalhadores entre um momento anterior e um momento posterior ao início da crise de Covid-19. Por exemplo, poderiam ser colocadas as seguintes restriçóes de elegibilidade para as empresas:

8. Isso pode ser implementado exigindo que o trabalhador contratado se valendo dessa medida não possa ter registro de emprego no e-social nos $X$ dias (parâmetro a definir) que antecedem a contratação. Também se pode exigir que o trabalhador não possa ser vinculado simultaneamente a mais de um contrato subsidiado. 
- mostrar no e-social um estoque médio de trabalhadores entre janeiro e maio de 2020 menor ou igual ao estoque médio nos mesmos meses de 2019; e/ou

- evidenciar no e-social um saldo negativo entre janeiro e maio de 2020. Note-se que esse critério contempla as empresas novas constituídas após o primeiro trimestre de 2019.

Por fim, durante a vigência do contrato subsidiado, a empresa estaria sujeita a algum tipo de restrição a demissóes sem justa causa.

\subsection{Considerações sobre os contratos e os subsídios}

1) Haveria duas modalidades de contratos por prazo determinado elegíveis para o subsídio: com jornada parcial conforme estipulado na Lei no $13.467 / 2017$, ou contrato com jornada integral até quarenta horas - embora a lei trabalhista permita contratos de até 44 horas, até mesmo o menor o incentivo seria limitado a contratos de até quarenta horas.

2) O subsídio seria maior (proporcionalmente) nas novas contrataçóes com jornada parcial.

3) Para novas contrataçóes feitas por empresas não optantes do sistema simplificado de impostos (Sistema Integrado de Pagamento de Impostos e Contribuiçóes das Microempresas e Empresas de Pequeno Porte-Simples Nacional), o subsídio seria implementado via desconto na contribuição patronal à Previdência Social. Por exemplo, 15 pontos percentuais (p.p.) de desconto no contrato com jornada parcial e 5 p.p. no contrato com jornada integral. Ou então uma alíquota ascendente - linearmente ou em faixas de quatro horas - para jornadas superiores a vinte horas.

4) Para novas contrataçóes feitas por empresas optantes do sistema simplificado de impostos (Simples Nacional), o subsídio seria implementado via desconto nas alíquotas destinadas ao Sistema $S$ e ao Salário-Educação - por exemplo, zerando ambas, o que equivale a um desconto de 5 p.p.

5) Os valores estipulados para o desconto podem diminuir gradualmente na duração do contrato e/ou no tempo do calendário - começando a diminuir em julho de 2021 ou após um ano de contrato.

\subsection{Considerações sobre possíveis fontes de recursos}

O financiamento pode vir de combinaçôes entre as seguintes alternativas.

1) Mudança no valor de remuneração aplicado a hora extra em qualquer modalidade de contrato. Esse valor passaria de $50 \%$ para $75 \%$, sendo $50 \%$ destinados ao trabalhador e $25 \%$, ao governo - além disso, pode ser explicitado que as desoneraçóes não se aplicam a contribuiçóes que incidem sobre horas extras.

2) Uma alíquota de $\mathrm{X} \%$ (parâmetro a definir) seria cobrada pelo governo federal em qualquer novo contrato que estipular jornada superior a 40 horas semanais, possivelmente apenas no montante de horas que exceder 40 horas. Por exemplo, os mesmos $25 \%$ estipulados acima na jornada semanal que passar de 40 horas. 
3) O abono salarial referente ao ano-base 2020 teria seu valor reduzido em $\mathrm{X} \%$, podendo a redução ser maior para trabalhadores que laboraram mais meses em 2020. Note-se que a previsão de pagamento do abono salarial referente ao ano-base 2020 aponta para o segundo semestre de 2021. Logo, seria redução de gasto que incidiria somente no orçamento de 2021.

4) Ao tramitar no Congresso Nacional, a conversão em lei da MP do contrato verde e amarelo previa entre suas fontes de financiamento as economias à previdência geradas pela reforma de 2019, que também podem compor o financiamento dessa proposta.

\section{CONCLUSÕES}

Em um contexto de grave crise sanitária, econômica e social em que a maioria da população em idade de trabalhar reporta não ter trabalhado por sequer uma hora no mês de maio, ainda que informalmente, novas medidas precisam ser adotadas para reverter ao menos parte da perda estimada de quase 10 milhóes de ocupaçóes em três meses.

Espera-se com este trabalho apresentar alternativas a serem avaliadas pela sociedade e por suas instâncias decisórias. A proposta aqui descrita envolve desonerar novas contrataçóes formais, com ênfase nas jornadas mais curtas, de modo a maximizar o número de postos e permitir revezamentos que minimizem o contágio pelo novo coronavírus.

Observou-se que os países mais desenvolvidos apresentam jornadas médias menores que a brasileira. Argumentou-se que o estímulo a contrataçóes de jornada reduzida tenderia a beneficiar proporcionalmente mais os que já se empregam com mais frequência em regimes de jornada parcial. Esses grupos abrangem justamente os mais vulneráveis no mercado de trabalho, com menores rendimentos médios e menor formalização, bem como os mais afetados economicamente pela crise atual. Mulheres, jovens - sobretudo estudantes -, idosos, menos escolarizados e informais seriam provavelmente os mais beneficiados, embora a desoneração possa facilitar a admissão de qualquer pessoa.

As potenciais fontes de financiamento vão além do subsídio cruzado e poderiam incluir combinaçóes de: $i$ ) mudança no valor de remuneração aplicado à hora extra em qualquer modalidade de contrato; ii) alíquota temporária extraordinária sobre as horas que excedam certo liminar de jornada; iii) redução no abono salarial a ser pago no segundo semestre de 2021; e iv) economias da reforma da previdência de 2019.

A crise global imposta pelo novo coronavírus requer novas estratégias que conciliem recuperação do nível de emprego e minimização de riscos à saúde da populaçáo. Quanto mais pessoas tiverem um trabalho formal remunerado, melhor será a recuperação econômica e social do país, com mais chances de reduzir de forma sustentável a pobreza e a desigualdade agravadas pela crise. Ao mesmo tempo, para qualquer tamanho de população ocupada que se consiga atingir, é melhor que os trabalhadores se distribuam no tempo e no espaço. Promover revezamentos em dias alternados, fins de semana prolongados, rodízios de folgas nos dias úteis e turnos alternativos para evitar os horários de pico de deslocamento são medidas que podem apoiar o controle da Covid-19 e que se tornam mais viáveis com cargas semanais menores. 


\section{REFERÊNCIAS}

BARBOSA, A. L. N. H.; COSTA, J. S.; HECKSHER, M. Mercado de trabalho e pandemia da Covid-19: ampliação de desigualdades já existentes? Mercado de Trabalho: conjuntura e análise, Rio de Janeiro, n. 69, 2020.

CARVALHO, S. S. Os efeitos da pandemia sobre os rendimentos do trabalho e o impacto do auxílio emergencial: o que dizem os microdados da PNAD Covid-19. Carta de Conjuntura, Rio de Janeiro, n. 48, 2020.

GARNERO, A. Are part-time workers less productive and underpaid? Bonn: IZA World of Labor, 2016.

GONZAGA, G. M.; MENEZES FILHO, N. A.; CAMARGO, J. M. Os efeitos da redução da jornada de trabalho de 48 para 44 horas semanais em 1988. Revista Brasileira de Educaçáo, Rio de Janeiro, v. 57, n. 2, p. 369-400, abr./jun. 2003.

IPEA - INSTITUTO DE PESQUISA ECONÔMICA APLICADA. Proposta 4.1 Implementação de programas de subsídio temporário à contratação de trabalhadores e renovação de programas de redução de jornada. In: . Brasil pós-Covid-19: contribuiçôes do Instituto de Pesquisa Econômica Aplicada. Brasília: Ipea, 2020, p. 66-69.

NERI, M. C. Workaholics, desempregados e jornada de trabalho. Valor Econômico, 13 jun. 2000 .

REIS, M.; COSTA, J. Jornada de trabalho parcial no Brasil. Mercado de Trabalho: conjuntura e análise, Rio de Janeiro, n. 61, p. 33-40, 2016. (Boletim Mercado de Trabalho).

\section{BIBLIOGRAFIA COMPLEMENTAR}

BOSCH, G.; LEHNDORFF, S. Working-time reduction and employment: experiences in Europe and economic policy recommendations. Cambridge Journal of Economics, v. 25, n. 2, p. 209-243, Feb. 2001.

DE SPIEGELAERE, S.; PIASNA, A. The why and how of working time reduction. Brussels: ETUI, 2017.

DOLTON, P. Working hours: past, present, and future. Bonn: IZA World of Labor, 2017. (Working Paper, n. 406). Disponível em: <https://is.gd/jj5IPK>.

EUROFOUND - EUROPEAN FOUNDATION FOR THE IMPROVEMENT OF LIVING AND WORKING CONDITIONS. Working time developments in the 21 st century: work duration and its regulation in the EU. Luxembourg: Eurofound, 2016.

Extending flexicurity: the potential of short-time working schemes. Luxembourg: Eurofound, 2010.

ILO - INTERNATIONAL LABOUR ORGANIZATIONW. Working time and productivity. Genève: ILO, June 2004.

MULliGAN, C. B. Shorter workweeks are likely in new year. The New York Times, New York, Jan. 2014.

. Policies that discourage full-time work. The New York Times, New York, Jan. 2014. 
OECD - ORGANISATION FOR ECONOMICCO-OPERATION AND DEVELOPMENT. Working hours: latest trends and policy initiatives. In: OECD - ORGANISATION FOR ECONOMICCO-OPERATION AND DEVELOPMENT. Employment Outlook 1998. Paris: OECD, 1998.

How good is part-time work? In: OECD - ORGANISATION FOR ECONOMICCOOPERATION AND DEVELOPMENT. Employment Outlook 2010. Paris: OECD, 2010. p. 211-266.

VARIAN, H. Automation versus procreation (aka bots versus tots). VOX ${ }^{\mathrm{EU}}$ CEPR, 30 Mar. 2020. Disponível em: <https://bit.ly/303ZUMQ>. 
